\title{
The Effect of Massage with Oils on the Growth of Term Infants: A Randomized Controlled Trial
}

\author{
Mandana Mirmohammadali1, Fatemeh Sadat Hosseini-Baharanchi' ${ }^{2,3}$, \\ Ziba Raisi Dehkordi4*, Reza Bekhradi5, Masoumeh Delaram4 \\ ${ }^{1}$ Department of Reproductive Health, School of Nursing and Midwifery, Tehran University of Medical Sciences, \\ Tehran, Iran \\ ${ }^{2}$ Department of Biostatistics, Faculty of Medical Sciences, Tarbiat Modares University, Tehran, Iran \\ ${ }^{3}$ Department of Mathematics, Eyvanakey Institute of Higher Education, Semnan, Iran \\ ${ }^{4}$ Department of Midwifery, School of Nursing and Midwifery, Shahrekord University of Medical Sciences, \\ Shahrekord, Iran \\ ${ }^{5}$ Research Development Unit Barij Essence Pharmaceutical Company, Kashan, Iran \\ Email: ${ }^{*}$ ziba758@gmail.com
}

Received 7 July 2015; accepted 1 September 2015; published 4 September 2015

Copyright (C) 2015 by authors and Scientific Research Publishing Inc.

This work is licensed under the Creative Commons Attribution International License (CC BY). http://creativecommons.org/licenses/by/4.0/

(c) (i)

Open Access

\section{Abstract}

Background and Aims: Infant massage could potentially benefit both physiological and psychological health. This study aims to determine the effect of massage with oils on the growth of full-term infants, which is given by their mothers. Study Design: This is a double-blind randomized controlled trial which was conducted on full term infants visited in the nine Public Health Centers of Shahrekord, Iran in 2010. Material and Methods: This study included 217 infants. Inclusion criteria for the infants were age scale between 10 to 15 days, full term gestation, birth weight of 2500 grams at least, Apgar score of 7 or above, no resuscitation after the birth, exclusive breastfeeding during the study, medically stable condition without any need for drugs, nulliparous. The infants were randomized into four groups: massage with sunflower oil, massage with sesame oil, massage without oil, and no massage (control group). Massage was given by mothers twice a day for 4 weeks, starting from the $10-15^{\text {th }}$ day of life. Weight and height were measured weekly. At last, Repeated Measures Analysis of Covariance was employed to analyze the data. Birth weight (height) as well as mean frequency of breastfeeding during the study was deemed as covariates. Results: The findings showed that the mean of weight and height was significantly different between groups over time, respectively $(P=0.005, P<0.001)$. The infants' mean weight in sunflower oil massage group increased significantly compared with other three groups $(P=0.005)$. In addition,

\footnotetext{
*Corresponding author.
} 
infants' height gain in sunflower and sesame oil massage group were significantly higher than message-only and control groups $(p<0.001)$. Conclusions: Massage with oil, especially sunflower oil is an inexpensive, simple, and effective intervention which improved weight and height gain in selected samples. Further studies are needed to evaluate the serious adverse effects, if any, to notify midwives and health care staff.

\title{
Keywords
}

\author{
Full Term Infant, Oil Massage, Growth, Repeated Measures Analysis of Covariance
}

\section{Introduction}

Infant massage could potentially benefit both physiological and psychological health [1]. Massage is one of the oldest therapeutic techniques in the world which has been used as a routine part of infant care in many cultures [2] [3]. The sense of touch is one of the first senses to develop, and parent-infant touch provides numerous benefits including regulation of heartbeat and temperature for babies as well as protection against infections. It also promotes parent-infant bonding and early social development [4] [5]. Teaching mothers to massage their infants may strengthen attachment by helping the mother to become more sensitive to her infant's cues and positive mother-infant interaction patterns. Furthermore, mothers who massage their neonates have lower depression and anxiety symptoms [5]-[7]. In many studies, infant massage was provided by researchers, nurses or other care providers; yet in several others, parents were taught to massage their infants at home [8]. One of the important effects of massage is promoting optimal infant growth and development [1] [7] [9]. Mechanisms of the massage therapy affecting weight gain are not yet known. Various possibilities have been proposed to explain the positive effects of massage on weight gain in preterm and full term infants including hormone growth, vagal tone and gastric motility, in addition to improved circulation of blood and lymph fluids; however, it has been suggested that further research is needed to confirm these mechanisms [10]. Moreover, oils have long been used for massage therapy [7] [9] i.e., topical oil application is recommended for improving skin barrier function [11], overall condition of the skin [12], providing moisture [13], antimicrobial activity [14], and reducing skin injury [15] [16]. In addition, the use of synthetic oil stimulates vagal activity, which may indirectly contribute to weight gain and increase in serum triglyceride levels of neonates [17]. Sometimes, it may have side effects in the form of skin rashes and bacterial colonization either [16]; accordingly, it is important to select a proper kind of oil in massage. Agarwal et al. showed that infants massaged with sesame oil achieved better somatic growth and improvement of blood flow than infants messaged with other oils. For this reason, they introduced sesame oil as the best oil for infant massage [18]. While other researchers have observed benefits for the use of sunflower oil in massage, such as fewer nosocomial infections and erythema plus improved skin hydration [12]. Sunflower oil contains high levels of essential fatty acids, particularly linoleic acid which then provides positive effect on life-quality parameters [12] [19]. Traditionally, infant massage using various oils has proved effective in the first months of infancy in Iran [20] [21]. The main aim of this study was to compare the effect of massage with different oils on infants' weight and height gain.

\section{Materials and Methods}

This randomized controlled trial was conducted on 217 full term infants. They were taken by their mothers for the routine two-week post-natal visit to the Public Health Centers of Shahrekord, Iran, from March to September 2010. The study was approved by the Ethics Committee of Tehran University of Medical Sciences (code: IRCT201102265912N1). Written consent was obtained from infants' parents. Inclusion criteria were age scale of 10 - 15 days, full term gestation, birth weight of 2500 grams or more, nulliparous, Apgar score of 7 or above with no resuscitation after the labour, exclusive breastfeeding during the study, and no intake of any drug or supplement except for vitamin AD according to the Manual of The Ministry of Health and Medical Education in Iran. The exclusion criteria were to have neonatal problems such as birth asphyxia, jaundice, infections, and disorders of adaptation, visible congenital malformations. Mothers with diabetes, heart diseases, pregnancy-induced hypertension, antepartum hemorrhage and any other illness were excluded from the study. Infants were 
left out of the study if they had medication discontinuation either.

Barij Essence Pharmaceutical Company provided 108 quite similar bottles for experimental groups. 54 bottles contained sesame oil and 54 were filled with sunflower oil. The massage-only group received massage without any oil and control group did not receive any massage and no oil.

Considering type I error equal to 0.05 , type II error 0.2 , variance of all observation 40 , correlation of 0.6 for repeated measures per subject, 4 number of repeated measures and effect size for $500 \mathrm{~g}$ weight gain, a sample of 198 subjects is needed [22]. About 217 subjects were recruited due to $10 \%$ loss of samples. Using NCSS PASS11 software, Procedure menu and DOE submenu, 217 infants were randomized into four groups through randomized block design. Mothers and data-analyst were blind.

\subsection{Massage Technique}

A standardized massage technique was used and in the beginning, mothers were supervised till they acquired the massage skill. On the subsequent days, 15 minute massage was given twice a day (morning and afternoon) for four weeks at their home. All mothers in the experimental groups were given a printed protocol for massage and asked to record whether they provided massage to their infant or not. They were also provided with an instructional CD about the procedure of infant massage consisting of all details such as force and direction, prepared by the researchers. Mothers were weekly monitored through calling and visiting at home by the researchers in order to ensure accurate massage procedure and to help if there was any complication. Massage was initiated one hour before feeding and the massage procedure could be modified according to the infant's response so as to avoid a negative reaction like crying, fidgeting or behavioral distress [23]. When the infant was in a quiet alert state, it was the best start massaging. If infant indicated that they were not in a good mood [m4], the massage was discontinued. The infant was positioned on a cotton blanket spread out over an infant massage mat. The massage was given to the face and head of the infant followed by arms, chest, abdomen, legs and feet, and lastly the back. The duration of each massage was 15 minutes which was performed twice a day. The infants in the oil massage groups received massage with $5 \mathrm{ml} / \mathrm{kg} /$ day divided equally between either of applications. The control group was only visited routinely at the health center. The mothers in the control group only used occasional touch for soothing their infant, and if there was given any structured massage or other sorts intervention to the infants, they were excluded from the study. The mothers in the control group were encouraged to visit the health center for the measurement of their infants' weight and height for the next four weeks by small gifts. Several visiting days were assigned for each group to prevent interference unless emergency occasions.

\subsection{Data Collection}

Parental characteristics including age and education level as well as type of delivery were recorded. Infants' characteristics consisted of sex and age. Infants' weight and height at the baseline and then for each of the next four weeks were measured as outcomes. Infants were weighed nude using Mechanical Baby Scale-Seca 745 (with an accuracy of \pm 5 grams) and their height was measured through an infant meter.

\subsection{Statistical Analysis}

Chi-square test and ANOVA were used to compare groups' characteristics. The analysis approach was a Repeated Measures Analysis of Covariance that permitted use of more than one postnatal weight and height measurement per infant. Birth-weight (height) and mean frequency of breastfeeding during the four weeks were included as covariates. Sphericity and other assumptions of the model were checked. Bonferroni and Tukey tests were applied as post-hoc tests whenever it was necessary. All analyses were performed using SPSS 16. All statistical tests were two-sided and conducted using a significance level of 0.05 .

\section{Results}

Of 217 infants who were randomized into four groups, 160 infants completed the study at the end of the $4^{\text {th }}$ week, 40 infants in each group. The clinical trial diagram is shown in Figure 1.

There were 78 (48.8\%) male infants. The infants mean \pm SD age, birth-weight, and birth-height were $13.7 \pm$ 1.8 days, $3115.1 \pm 424.8$ grams, and $49.8 \pm 4.1 \mathrm{~cm}$, respectively. The mothers' and fathers' mean \pm SD age were $27.2 \pm 4.2$ and $30.9 \pm 4.7$, respectively. Table 1 presents a summary of infants and their parents' characteristics. 


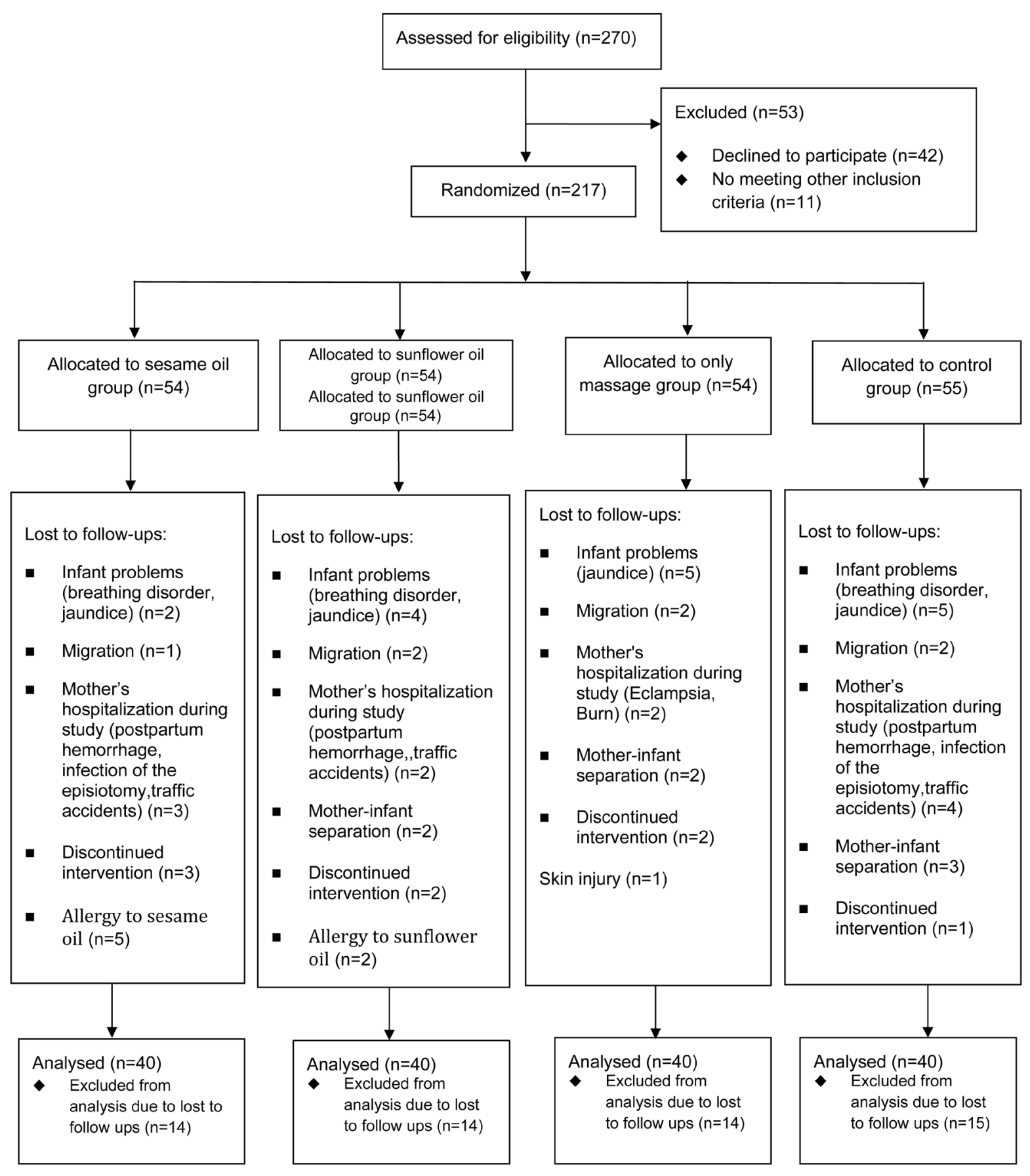

Figure 1. Clinical trial diagram.

Parents' and infants' characteristics were similar between groups except mean frequency of breastfeeding during 4 weeks which was statistically different between groups (Table 1).

Table 2 shows weight and height mean \pm SD of infants at birth, $1^{\text {st }}, 2^{\text {nd }}, 3^{\text {rd }}$ and $4^{\text {th }}$ week for four groups. Mean weight and height were compared between different groups as well as over time, separately. The results are shown using capital and small letters in Table 2. The findings revealed that mean weight and mean height was significantly different between consequent time points in each intervention group $(\mathrm{P}<0.05)$. In addition, mean weight was significantly different between four groups in $3^{\text {rd }}$ and $4^{\text {th }}$ week, and mean height was different between four groups in $2^{\text {nd }}$, $3^{\text {rd }}$ and $4^{\text {th }}$ week, respectively $(\mathrm{P}<0.05)$. 
Table 1. Comparison between characteristics of the study infants and their parents in four groups.

\begin{tabular}{|c|c|c|c|c|c|}
\hline characteristics & Sesame oil massage & Sunflower oil massage & Massage-only & Control & $\mathrm{P}$ \\
\hline Infant age (day) & $13.42 \pm 2.44$ & $13.85 \pm 1.68$ & $13.95 \pm 1.44$ & $13.67 \pm 1.60$ & 0.59 \\
\hline Mother's age & $27.70 \pm 4.02$ & $27.58 \pm 4.74$ & $26.58 \pm 4.46$ & $27.23 \pm 3.77$ & 0.64 \\
\hline Father's age & $31.82 \pm 4.60$ & $30.77 \pm 4.78$ & $30.35 \pm 5.02$ & $31.02 \pm 4.28$ & 0.55 \\
\hline Birth weight (gr) & $3139.2 \pm 379.54$ & $3145.6 \pm 402$ & $3069 \pm 528.8$ & $3106.6 \pm 383.1$ & 0.84 \\
\hline Birth height (cm) & $48.97 \pm 7.85$ & $50.17 \pm 1.5$ & $49.90 \pm 1.54$ & $50.23 \pm 1.55$ & 0.50 \\
\hline $\begin{array}{l}\text { Frequency of breast } \\
\text { feeding (times per day) }\end{array}$ & $11.5 \pm 1.3$ & $12.4 \pm 0.5$ & $11.6 \pm 1.4$ & $12.4 \pm 0.5$ & $<0.001$ \\
\hline Infant's sex & & & & & 0.17 \\
\hline Female & $24(60)$ & $17(42.5)$ & $24(60)$ & $17(52.5)$ & \\
\hline Male & $16(40)$ & $23(57.5)$ & $16(40)$ & $23(57.5)$ & \\
\hline Type of delivery & & & & & 0.61 \\
\hline Full term & $16(40)$ & $19(47.5)$ & $18(45)$ & $18(45)$ & \\
\hline Caesarean section & $24(60)$ & $21(52.5)$ & $22(55)$ & $22(55)$ & \\
\hline Mother's education & & & & & 0.54 \\
\hline Diploma and less & $25(62.5)$ & $21(52.5)$ & $26(65)$ & $21(52.5)$ & \\
\hline Higher than diploma & $15(37.5)$ & $19(47.5)$ & $14(35)$ & $19(47.5)$ & \\
\hline Father's education & & & & & 0.88 \\
\hline Diploma and less & $26(65)$ & $24(60)$ & $29(72.5)$ & $31(77.5)$ & \\
\hline Higher than diploma & $14(35)$ & $16(40)$ & $11(27.5)$ & $9(22.5)$ & \\
\hline
\end{tabular}

Table 2. Infant weight and height mean \pm SD of infants at birth, $1^{\text {st }}, 2^{\text {nd }}, 3^{\text {rd }}$ and $4^{\text {th }}$ week.

\begin{tabular}{|c|c|c|c|c|c|}
\hline \multirow[b]{3}{*}{ Group $^{\dagger}$} & \multicolumn{5}{|c|}{ Time $^{*}$} \\
\hline & At birth ${ }^{* *}$ & $1^{\text {st }}$ week & $2^{\text {nd }}$ week & $3^{\text {rd }}$ week & $4^{\text {th }}$ week \\
\hline & & & & & \\
\hline \multicolumn{6}{|l|}{ Weight } \\
\hline Control & $3378.2 \pm 354.16$ & ${ }^{\mathrm{A}} 3483.7 \pm 392.4^{\mathrm{a}}$ & ${ }^{\mathrm{A}} 3606.2 \pm 407.1^{\mathrm{ab}}$ & ${ }^{\mathrm{A}} 3700 \pm 403.6^{\mathrm{ab}}$ & ${ }^{\mathrm{A}} 3778.7 \pm 432.7^{\mathrm{b}}$ \\
\hline Sesame oil & $33,050 \pm 368.25$ & ${ }^{\mathrm{A}} 3568.7 \pm 404.4^{\mathrm{a}}$ & ${ }^{\mathrm{A}} 3811.2 \pm 414.7^{\mathrm{ab}}$ & $\mathrm{AB}_{4023.7} \pm 410.9^{\mathrm{b}}$ & $\mathrm{BC}_{4341.2 \pm 467.9 \mathrm{C}}$ \\
\hline $\begin{array}{l}\text { Sunflower } \\
\text { oil }\end{array}$ & $3469.5 \pm 466.3$ & ${ }^{\mathrm{A}} 3586.7 \pm 503.8^{\mathrm{a}}$ & ${ }^{\mathrm{A}} 3850 \pm 605.5^{\mathrm{ab}}$ & ${ }^{\mathrm{B}} 4131.2 \pm 657.3^{\mathrm{bc}}$ & ${ }^{\mathrm{C}} 4408.5 \pm 714.1^{\mathrm{c}}$ \\
\hline Placebo & $3339.16 \pm 317.37$ & ${ }^{\mathrm{A}} 3527.5 \pm 361.4^{\mathrm{a}}$ & ${ }^{\mathrm{A}} 3690 \pm 374.5^{\mathrm{a}}$ & ${ }^{\mathrm{A}} 3868.5 \pm 416.7^{\mathrm{a}}$ & ${ }^{\mathrm{B}} 4094.2 \pm 420.3^{\mathrm{b}}$ \\
\hline \multicolumn{6}{|l|}{ Height } \\
\hline Control & $50.5 \pm 1.4$ & ${ }^{\mathrm{A}} 51 \pm 1.2^{\mathrm{a}}$ & ${ }^{\mathrm{A}} 51.5 \pm 1.2^{\mathrm{a}}$ & ${ }^{\mathrm{A}} 52.2 \pm 1.1^{\mathrm{b}}$ & ${ }^{\mathrm{A}} 52.6 \pm 1.1^{\mathrm{b}}$ \\
\hline Sesame oil & $51 \pm 1.6$ & ${ }^{\mathrm{B}} 52 \pm 1.7^{\mathrm{a}}$ & ${ }^{\mathrm{B}} 52.8 \pm 1.6^{\mathrm{ab}}$ & ${ }^{\mathrm{B}} 53.6 \pm 1.6^{\mathrm{b}}$ & ${ }^{\mathrm{B}} 54.8 \pm 1.6^{\mathrm{c}}$ \\
\hline $\begin{array}{l}\text { Sunflower } \\
\text { oil }\end{array}$ & $50.4 \pm 1.5$ & ${ }^{\mathrm{B}} 52 \pm 1.6^{\mathrm{a}}$ & ${ }^{\mathrm{B}} 53 \pm 1.7^{\mathrm{ab}}$ & ${ }^{\mathrm{B}} 53.7 \pm 1.8^{\mathrm{bc}}$ & ${ }^{\mathrm{B}} 54.5 \pm 2.2^{\mathrm{c}}$ \\
\hline Placebo & $50.1 \pm 1.5$ & ${ }^{\mathrm{A}} 51 \pm 1.5^{\mathrm{a}}$ & ${ }^{\mathrm{A}} 51.6 \pm 1.5^{\mathrm{ab}}$ & ${ }^{\mathrm{A}} 52.3 \pm 1.4^{\mathrm{bc}}$ & ${ }^{\mathrm{A}} 53.1 \pm 1.4^{\mathrm{c}}$ \\
\hline
\end{tabular}

*Times that do not share a small letter are significantly different; ${ }^{* *}$ Measurements are not included in the analysis; ${ }^{\dagger}$ Massage groups that do not share capital letter are significantly different.

Figure 2 and Figure 3 illustrate trend of infant's mean weight and height in four groups over time respectively.

Repeated measures analysis taking into account group and time effects simultaneously showed that mean weight and height increased significantly in four groups over time, respectively $(\mathrm{P}=0.001, \mathrm{P}=0.005)$. More 


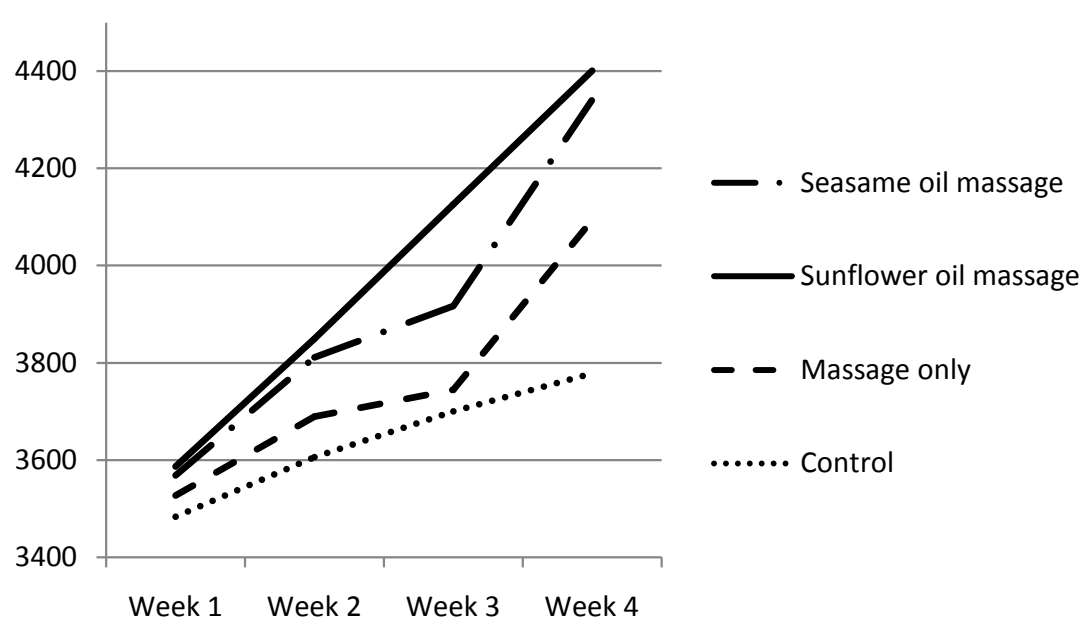

Figure 2. Trend of infants' mean weight in four groups over time.

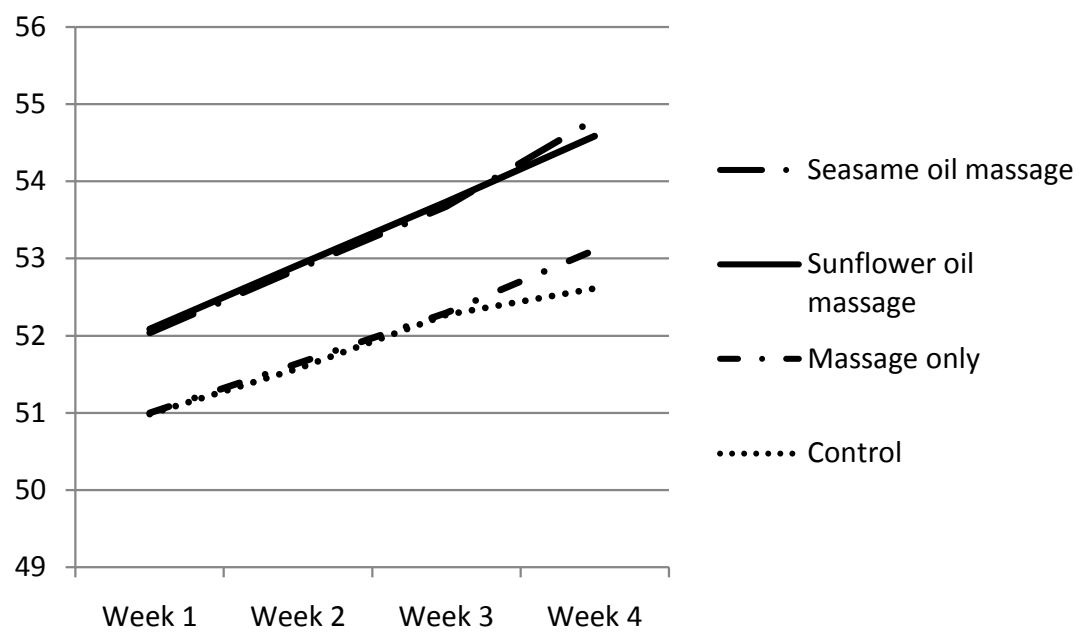

Figure 3. Trend of infants' mean height in four groups over time.

comparisons detected that the infants who received sunflower oil massage had a significant higher mean weight compared with the control group $(\mathrm{P}=0.005)$. The infants in sunflower oil massage group experienced a better weight gain velocity in comparison to the sesame oil massage group, although the difference was not statistically significant. In addition, infants who administered to sunflower and sesame oil massage had a similar height gain trend, and also, massage-only and control group were similar ( $\mathrm{P}>0.05)$. However, infants in sesame and sunflower oil massage groups experienced a better height gain in comparison to the infants in massage-only and control group $(\mathrm{P}<0.001)$.

\section{Discussion}

Although a number of massage therapy studies on preterm infants have been conducted, there are limited studies assessing the effects of massage therapy on term infants in Iran. The rationale of this study was that the massage by mother might be one of the effective methods on promoting an infant's growth. Massage therapy has led to weight gain in preterm infants and increase in bone density [17]. Infant massage is a way of comforting skin inputs and nourishment for the healthy development of mind, body and spirit [24]. Research on ways of delivering the massage is also explored including using mothers versus therapists and the additional benefits of using oils. It was shown that the role of mothers the same as therapists was effective [8]. Topical oil massage is routinely practiced in many countries [25]. Application of a barrier such as oil or emollient prevents insensible water loss from the skin [16] [26]. Plus, the use of synthetic oil increases vagal activity, which may indirectly contribute to 
weight gain [17]. Infant weight gain is associated with duration of breastfeeding and the timing of complementary food introduction [27].

The results of this study showed that the infant's weight rose through massage with sunflower oil, and infant's height increased as a result of massage with sunflower oil and sesame oil over the time. Weight and height gain velocity in either massage-only or the control group was significantly different from oil massage groups. This suggests transcutaneous absorption of vegetable oil through the infant's skin. The skin of a preterm infant allows significant absorption of fat; since it is thinner and more vascular [28]. This may also result in greater caloric intake and consequently a better weight gain [11]. Agarwal et al. reported that the massage improved the growth in full term healthy infants compared to infants without massage. They demonstrated that, of four different oils (herbal, mustard, sesame, and mineral), sesame oil improved growth in 2-month infants compared to the control group [18]. Yilmaz et al., suggested that body weight and height gain were higher in the massage group compared to the control group after 2 to 14 weeks of massage [29]. The height gain velocity was also significantly higher in the sesame oil and sunflower oil subgroups compared to other subgroups. However, the difference of average height increase between the participants of sesame oil and sunflower oil groups was not statistically significant. According to Soriano et al., significant height gain was observed in preterm infants after 30 days of oil massage [5]. Agarwal et al., reported significant increase in height among term infants after a 6 week massage [18]. In contrast, Arora et al. reported a non-significant effect of oil massage on height of preterm babies in an oil massage group [30]. Also, Roosbahani and Narenji compared the effects of massaging with sesame oil with no massaging on term infants, and found no statistically significant difference between the groups [21]. In this study, no relationship was found between infant weight (height) gain and gender likewise [5] [18] [31].

Although the present study indicated that massage application with oil had a potential to promote infants' growth, the observed benefit was probably because of the tactile kinesthetic stimulation rather than the oil used. To tell about the limitations, although the massage procedure was controlled by the researcher, quality of massage might have been different; inasmuch as, each mother gave massage to her own infant. As a consequence, it is partly difficult to conclude that the massage clearly promoted weight and height. It was observed some adverse events in the oil massage groups, however they were mild rash, which required no cessation. It goes without saying that massage is an easy and cost-effective practice which can be included as a part of the overall package of early infant intervention in infants' homecare thereby enhancing the growth. Moreover, probably due to the culture of small cities in Iran such as Shahrekord, mothers were young (27.2 \pm 4.2 years) at the time they bore the first baby; as such, they were motivated enough to follow the study. Such motivations may not be satisfying in developed countries where mothers are usually elder and occupied.

All things considered, if caregivers and health professionals conducting deliveries use inexpensive and readily available sunflower and sesame oil massage, it can be beneficial to the newborns and this practice could have substantial public-health benefits.

\section{Acknowledgements}

We sincerely appreciate all mothers who participated in the study.

\section{Conflict of Interest}

The authors declare that there is no conflict of interests.

\section{References}

[1] Underdown, A., Barlow, J., Chung, V. and Stewart-Brown, S. (2006) Massage Intervention for Promoting Mental and Physical Health in Infants Aged under Six Months. The Cochrane Database of Systematic Reviews, Cd005038. http://dx.doi.org/10.1002/14651858.cd005038.pub2

[2] Bond, C. (2002) Positive Touch and Massage in the Neonatal Unit: A British Approach. Seminars in Neonatology, 7, 477-486.

[3] Field, T., Grizzle, N., Scafidi, F., Abrams, S., Richardson, S., Kuhn, C., et al. (1996) Massage Theraphy for Infants of Depressed Mothers. Infant Behavior and Development, 19, 107-112. http://dx.doi.org/10.1016/S0163-6383(96)90048-X

[4] Vincent, S. (2011) Skin-to-Skin Contact. Part Two: The Evidence. The Practising Midwife, 14, 44-46.

[5] Serrano, M.S.C., Doren, F.M. and Wilson, L. (2010) Teaching Chilean Mothers to Massage Their Full-Term Infants: 
Effects on Maternal Breast-Feeding and Infant Weight Gain at Age 2 and 4 Months. The Journal of Perinatal \& Neonatal Nursing, 24, 172-181. http://dx.doi.org/10.1097/JPN.0b013e3181db5377

[6] Carter-Jessop, L. (1981) Promoting Maternal Attachment through Prenatal Intervention. MCN: The American Journal of Maternal/Child Nursing, 6, 107-112. http://dx.doi.org/10.1097/00005721-198103000-00009

[7] Kulkarni, A., Kaushik, J.S., Gupta, P., Sharma, H. and Agrawal, R. (2010) Massage and Touch Therapy in Neonates: The Current Evidence. Indian Pediatrics, 47, 771-776. http://dx.doi.org/10.1007/s13312-010-0114-2

[8] Field, T., Hernandez-Reif, M., Diego, M., Feijo, L., Vera, Y. and Gil, K. (2004) Massage Therapy by Parents Improves Early Growth and Development. Infant Behavior and Development, 27, 435-442. http://dx.doi.org/10.1016/j.infbeh.2004.03.004

[9] Vickers, A., Ohlsson, A., Lacy, J.B. and Horsley, A. (2000) Massage for Promoting Growth and Development of Preterm and/or Low Birth-Weight Infants. The Cochrane Database of Systematic Reviews, Cd000390. http://dx.doi.org/10.1002/14651858.cd000390.pub2

[10] Lee, H.-K. (2006) The Effects of Infant Massage on Weight, Height, and Mother-Infant Interaction. Journal of Korean Academy of Nursing, 36, 1331-1339.

[11] Darmstadt, G., Mao-Qiang, M., Chi, E., Saha, S., Ziboh, V., Black, R., et al. (2002) Impact of Topical Oils on the Skin Barrier: Possible Implications for Neonatal Health in Developing Countries. Acta Paediatrica, 91, 546-554. http://dx.doi.org/10.1111/j.1651-2227.2002.tb03275.x

[12] Darmstadt, G.L., Saha, S.K., Ahmed, A., Chowdhury, M., Law, P.A., Ahmed, S., et al. (2005) Effect of Topical Treatment with Skin Barrier-Enhancing Emollients on Nosocomial Infections in Preterm Infants in Bangladesh: A Randomised Controlled Trial. The Lancet, 365, 1039-1045. http://dx.doi.org/10.1016/S0140-6736(05)74228-8

[13] Blanken, R., Vilsteren, M., Tupker, R. and Coenraads, P. (1989) Effect of Mineral Oil and Linoleic-Acid-Containing Emulsions on the Skin Vapour Loss of Sodium-Lauryl-Sulphate-Induced Irritant Skin Reactions. Contact Dermatitis, 20, 93-97. http://dx.doi.org/10.1111/j.1600-0536.1989.tb03114.x

[14] Darmstadt, G.L., Badrawi, N., Law, P.A., Ahmed, S., Bashir, M., Iskander, I., et al. (2004) Topically Applied Sunflower Seed Oil Prevents Invasive Bacterial Infections in Preterm Infants in Egypt: A Randomized, Controlled Clinical Trial. The Pediatric Infectious Disease Journal, 23, 719-725. http://dx.doi.org/10.1097/01.inf.0000133047.50836.6f

[15] Edwards, W., Conner, J., Soll, R. and Network, V.O. (2001) The Effect of Aquaphor Original Emollient Ointment on Nosocomial Sepsis Rates and Skin Integrity in Infants of Birth Weight 501 to 1000 Grams. Pediatric Research, 49, 388-393.

[16] Nopper, A.J., Horii, K.A., Sookdeo-Drost, S., Wang, T.H., Mancini, A.J. and Lane, A.T. (1996) Topical Ointment Therapy Benefits Premature Infants. The Journal of Pediatrics, 128, 660-669. http://dx.doi.org/10.1016/S0022-3476(96)80132-6

[17] Field, T., Diego, M. and Hernandez-Reif, M. (2010) Preterm Infant Massage Therapy Research: A Review. Infant Behavior and Development, 33, 115-124. http://dx.doi.org/10.1016/j.infbeh.2009.12.004

[18] Agarwal, K., Gupta, A., Pushkarna, R., Bhargava, S., Faridi, M. and Prabhu, M. (2000) Effects of Massage \& Use of Oil on Growth, Blood Flow \& Sleep Pattern in Infants. The Indian Journal of Medical Research, 112, 212-217.

[19] Eichenfield, L.F., McCollum, A. and Msika, P. (2009) The Benefits of Sunflower Oleodistillate (SOD) in Pediatric Dermatology. Pediatric Dermatology, 26, 669-675. http://dx.doi.org/10.1111/j.1525-1470.2009.01042.x

[20] Badiee, Z., Samsamshariat, S. and Pourmorshed, P. (2011) Massage Therapy by Mother or Nurse: Effect on Weight Gain in Premature Infants. Journal of Isfahan Medical School, 29, 804-810.

[21] Roosbahani, N. and Narenji, F. (2008) Effect of Massage on Growth and Sleep Patern of Infants. Semnan University of Medical Sciences Journal, 4, 274-279.

[22] Diggle, P., Heagerty, P., Liang, K.-Y. and Zeger, S. (2002) Analysis of Longitudinal Data. Oxford University Press, Oxford.

[23] Burns, K., Cunningham, N., White-Traut, R., Silvestri, J. and Nelson, M.N. (1994) Infant Stimulation: Modification of an Intervention Based on Physiologic and Behavioral Cues. Journal of Obstetric, Gynecologic, \& Neonatal Nursing, 23, 581-589. http://dx.doi.org/10.1111/j.1552-6909.1994.tb01924.x

[24] Mainous, R.O. (2002) Infant Massage as a Component of Developmental Care: Past, Present, and Future. Holistic Nursing Practice, 17, 1-7. http://dx.doi.org/10.1097/00004650-200210000-00004

[25] Darmstadt, G.L. and Saha, S.K. (2002) Traditional Practice of Oil Massage of Neonates in Bangladesh. Journal of Health, Population and Nutrition, 20, 184-188.

[26] Pabst, R.C., Starr, K.P., Qaiyumi, S., Schwalbe, R.S. and Gewolb, I.H. (1999) The Effect of Application of Aquaphor on Skin Condition, Fluid Requirements, and Bacterial Colonization in Very Low Birth Weight Infants. Journal of Perinatology: Official Journal of the California Perinatal Association, 19, 278-283. 
http://dx.doi.org/10.1038/sj.jp.7200157

[27] Baker, J.L., Michaelsen, K.F., Rasmussen, K.M. and Sørensen, T.I. (2004) Maternal Prepregnant Body Mass Index, Duration of Breastfeeding, and Timing of Complementary Food Introduction Are Associated with Infant Weight Gain. The American Journal of Clinical Nutrition, 80, 1579-1588.

[28] Sankaranarayanan, K., Mondkar, J., Chauhan, M., Mascarenhas, B., Mainkar, A. and Salvi, R. (2005) Oil Massage in Neonates: An Open Randomized Controlled Study of Coconut versus Mineral Oil. Indian Pediatrics, 42, 877-884.

[29] Yilmaz, H.B. and Conk, Z. (2009) The Effect of Massage by Mothers on Growth in Healthy Full Term Infants. International Journal of Human Sciences, 6, 969-977.

[30] Arora, J., Kumar, A. and Ramji, S. (2005) Effect of Oil Massage on Growth and Neurobehavior in Very Low Birth Weight Preterm Neonates. Indian Pediatrics, 42, 1092-1100.

[31] Javadifar, N., Faal, S.S., Tadayon, M. and Dehdashtian, M. (2009) The Effect of Massage with Coconut Oil on Weight Gain in Preterm Neonate. Scientific Medical Journal, 2, 247-254. 